\title{
A Comparative Study between Superior Pedicle (Modified Lejour) and Medial Pedicle (Findlay) Reduction Mammoplasty Technique from the Aesthetic Point of View
}

\author{
MOHAMED O. SAAD EL-DIN, M.S.; KHALED M. EL-SHERBENY, M.D.; NADA A. MAHMOUD, M.D.; \\ KARIM K. EL-LAMIE, M.D. and ASHRAF M. FARID, M.D. \\ The Department of Plastic, Reconstructive, Burn and Maxillofacial Surgery, Faculty of Medicine, Ain Shams University
}

\begin{abstract}
Background: There are significant changes in breast shape and contour during the $1^{\text {st }}$ post-operative year after any breast reduction technique. Our work was dedicated to study the post-operative changes and aesthetic outcome in the superior and medial pedicle vertical scar reduction mammoplasty techniques.
\end{abstract}

Patients and Methods: The study was conducted on 20 female patients suffering from bilateral large breasts. They were divided equally into two groups using simple randomization. Group I (10 patients) were operated upon by superior pedicle (modified Le Jour) technique. Group II (10) patients were operated upon by medial pedicle (hall-findlay) technique. Patients were evaluated for esthetic outcomes. This was done through breast measurements and photographic analysis preoperatively, 1, 3 and 6 months post-operatively.

Results: There is no significant difference between group I and group II regarding the pre-operative measurements and intra-operative scar length. However, a significant difference was present between both groups for all measurements except IMF level at 3 and 6 months post-operatively. There is no significant difference in the photographic analysis.

Conclusion: Both techniques are aesthetically reliable with more bottoming out in findlay technique. Lower pole show is less in modified Lejour technique. Also, two new breast measurements were introduced.

Key Words: Modified lejour - Findlay technique.

\section{INTRODUCTION}

Breast reduction is one of the most frequent performed plastic surgery operations. Various areolar pedicles had been described, including the superior pedicle, horizontal bipedicle, lateral pedicle, vertical bipedicle, inferior pedicle and medial pedicle. Reliability of dermoglandular pedicle vascularity varies with different techniques which affects the final outcome [1].

In the early 1990s, Lejour [2] introduced her technique of vertical mammoplasty. Her approach included adjustable skin markings, initial liposuction for volume reduction, and extensive lower lateral breast skin undermining.

Hall Findley in 1999 [3] described her technique using superomedial pedicle with removal of a Cshaped skin and gland from the breast, the pedicle is rotated into position and the medial and lateral breast pillars are closed ending up in a vertical scar.

There are significant changes in breast shape and contour during the $1^{\text {st }}$ post-operative year after any breast reduction technique. Evaluation of these changes including upper pole fullness, breast projection, and bottoming-out, is made difficult by the absence of a practical definition of these entities and lack of a standardized system for measuring breast shape and assessing surgical results [4].

No detailed study had yet been performed to objectively compare the post-operative morphological changes that occur after superior pedicle and medial pedicle vertical scar mammoplasty techniques. In this work we used surface measurements for evaluation of both techniques.

Our work was dedicated to compare the superior versus medial pedicle vertical mammoplasty techniques regarding the aesthetic outcome point of view.

\section{PATIENTS AND METHODS}

This study was conducted in the Department of Plastic, Burn and Maxillofacial Surgery, Ain Shams University between (January 2015 and February 2018) on 20 female patients, their age ranged from (20-50 years). All of them suffered from bilateral large breasts. They were divided 
equally into two groups using simple randomization. Group I comprised 10 patients that were operated upon by superior pedicle (modified Lejour) technique where no liposuction nor skin undermining were done. Group II comprised 10 patients that were operated upon by medial pedicle (hall-findlay) technique.

A pre-operative sonomammography was done for each patient to rule out any breast pathology.

Patients with SN-N distance $35 \mathrm{~cm}$ or less were included in the study while patients with concomitant systemic illness, previous breast surgery and BMI more than 35 were excluded from the study.

\section{Aesthetic outcome evaluation:}

Aesthetic outcome was evaluated by taking measurements clinically and photographic analysis.

Clinical measurements were done through different breast measurements as nipple position, nipple projection, upper pole slope (fullness), lower pole length, lower pole show, length of the scar, infra mammary fold level. All these measurements were assessed and compared pre-operatively then after 1, 3 and 6 months post-operative except the length of the scar which was measured immediate post-operative and compared after 1, 3 and 6 months.

- Nipple position (SN-N distance) Fig. (1A).

- Nipple projection (NP): During drawing the breast markings, with the arm abducted $90^{\circ}$ a line is drawn from the apex of the axilla along the chest wall representing the Midaxillary Line (MAL). The perpendicular distance from this line to the nipple was measured pre-operatively and after 1, 3 and 6 months post-operatively Fig. (1B).

- Upper pole slope (fullness): This is a new described measurement, while the patient is in the lateral position, 2 points were marked. The first point is $2 \mathrm{~cm}$ and the second point is $5 \mathrm{~cm}$ above the upper border of the areola. The vertical distance of these points to the midaxillary line were measured pre-operatively and re-evaluated after 1, 3 and 6 months Fig. (1C,D).

- Lower pole show: This is a new measurement where a ruler placed tangent to the lower curve of the breast. The distance from the lower border of the areola to the ruler was measured. This was mainly for evaluation of the progressive glandular ptosis in each technique Fig. (1E).

- Lower pole length: While patient lying on her back the breast was put under maximal stretch and the distance between the lower border of the areola to the IMF was measured pre-operatively then after 1, 3 and 6 months post-operative Fig. (1F).

- Infra mammary fold level: Using a tape a transverse line was drawn at the level of the IMF and the distance from the sternal notch to the point of intersection was measured pre-operative and after 1, 3 and 6 months Fig. (1G).

- Length of the scar was measured immediate postoperative and compared after 1, 3 and 6 months.

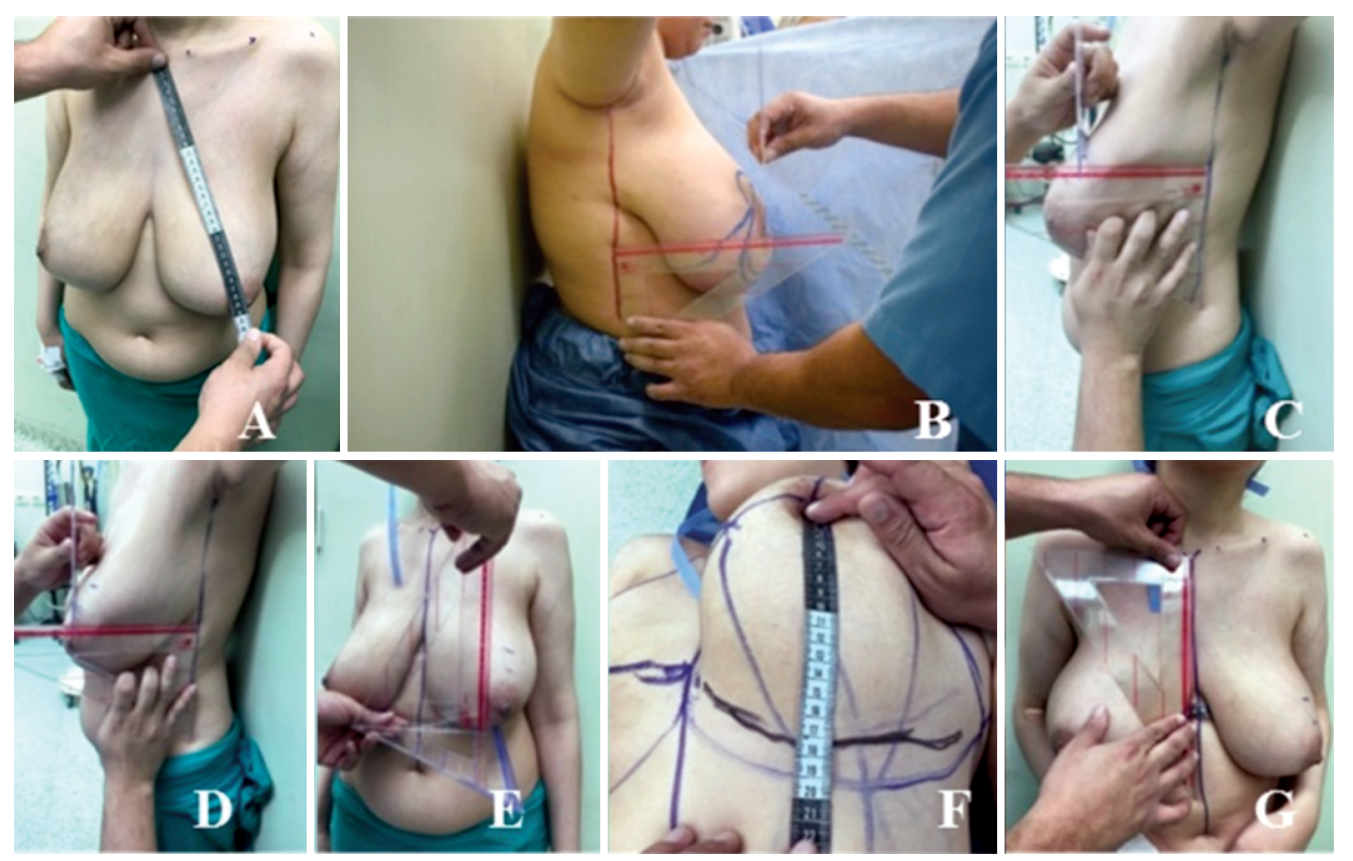

Fig. (1): (A) (SN-N distance), (B) (Nipple projection), (C,D) (Upper pole slope at $2 \mathrm{~cm}$ and $5 \mathrm{~cm}$ respectively), (E) (Lower pole show), (F) (Lower pole length), (G) (IMF level). 
Photography analysis was done through evaluation of pre and 6 months post-operative photographs taken in front, oblique and lateral view by 5 observer not sharing in the study. They were ( 2 plastic surgeon, 2 residents and 1 nurse). The points of evaluation were nipple position, areola size, scars, projection, shape of the breast, size (adequacy of reduction). The five observer used a Likert scale for assessment $1=$ very poor, $2=$ poor, $3=$ mediocre, $4=$ satisfactory, $5=$ good, $6=$ very good, $7=$ excellent).

\section{Complications:}

All complication occurred were recorded and compared between groups I and group II.

\section{Statistical analysis:}

Data were analyzed using Statistical Program for Social Science (SPSS) Version 20.0. Quantitative data were expressed as mean \pm Standard Deviation (SD). Qualitative data were expressed as frequency and percentage. The tests used were $t$-test, Least Significant Difference (LSD), and $p$-value test when $p$-value was $<0.05$ it considered significant.

\section{RESULTS}

The mean age of the patients in group I was (38.11 \pm 10.35$)$ the mean BMI was $(30.17 \pm 3.63)$ and the mean resection weight was $1050 \mathrm{~g}$ (range: $800-1300 \mathrm{~g}$ ) while in group II the mean age of the patients was $(39.25 \pm 9.45)$, the mean BMI was $(29.11 \pm 3.95)$ and the mean resection weight was 900g (range: 600-1200g).

\section{Aesthetic outcome evaluation:}

\section{Clinical measurements:}

There is no significant difference between group I and group II regarding the pre-operative measurements and intra-operative scar length ( $p$-value $>0.05$ ) as shown in (Table 1).

One month after surgery all the measurements including $\mathrm{SN}-\mathrm{N}$ distance, nipple projection, slope at $2 \mathrm{~cm}$, slope at $5 \mathrm{~cm}$, IMF level, lower pole distance and scar length decreased except for the lower pole show which increased in both groups and there was no significant difference between both groups ( $p$-value >0.05) (Table 2).

At 3 months post-operatively the $\mathrm{SN}-\mathrm{N}$ distance increased in group I, while it decreased in group II with statistically significant difference between both groups $(p<0.001)$ (Table 3$)$.

The nipple projection and slope at $2 \mathrm{~cm}$ and $5 \mathrm{~cm}$ from upper border of the areola which represents the upper pole fullness decreased in both groups, with significant difference between both $(p=0.042$, $p=0.044, p=0.043$ ) respectively (Table 3 ).
The IMF level did not change in group I, while it decreased in group II with no significant difference between both groups ( $p=0.097)$ (Table 3$)$.

The lower pole show decreased in group I, while it increased in group II with significant difference between groups $(p<0.001)$ (Table 3$)$.

Lower pole distance increased in both groups with a significant difference between them ( $p=$ 0.005) (Table 3).

Scar length decreased in both groups with a significant difference between them $(p=0.004)$ (Table 3).

At 6 months post-operatively, the $\mathrm{SN}-\mathrm{N}$ distance in group I increased, while it decreased in group II with statistically significant difference between both groups $(p<0.001)$ (Table 4$)$.

The nipple projection and slope at $2 \mathrm{~cm}$ and $5 \mathrm{~cm}$ from upper border of the areola which represents the upper pole fullness decreased in both groups with significant difference between both ( $p=0.049, p=0.037, p=0.033$ ) (Table 4).

The IMF level didn't change in group I and group II with no significant difference between both groups ( $p=0.223$ ) (Table 4).

The lower pole show decreased in group I while increased in group II with significant difference between groups $(p<0.001)$ (Table 4$)$.

Lower pole distance increased in both groups with a significant difference between them $(p=$ 0.002) (Table 4).

Scar length in group I decreased in both groups with a significant difference between them ( $p=$ 0.004) (Table 4).

\section{Photographic analysis:}

It was done by five evaluators assessing the overall shape, nipple position, areola size, scars, projection and adequacy of reduction on 20 patients comparing the preoperative photos with 6 months post-operative photos.

Although the average scores were slightly higher for group II, they were not statistically higher than group I $(p>0.005)$ (Table 5).

\section{Complications:}

Complications in group I includes superficial wound dehiscence in two breasts, infection and glandular necrosis in one breast compared to two breasts with superficial wound dehiscence and one breast with partial loss of NAC in group II. No hematoma or seroma found in this study in both groups. 

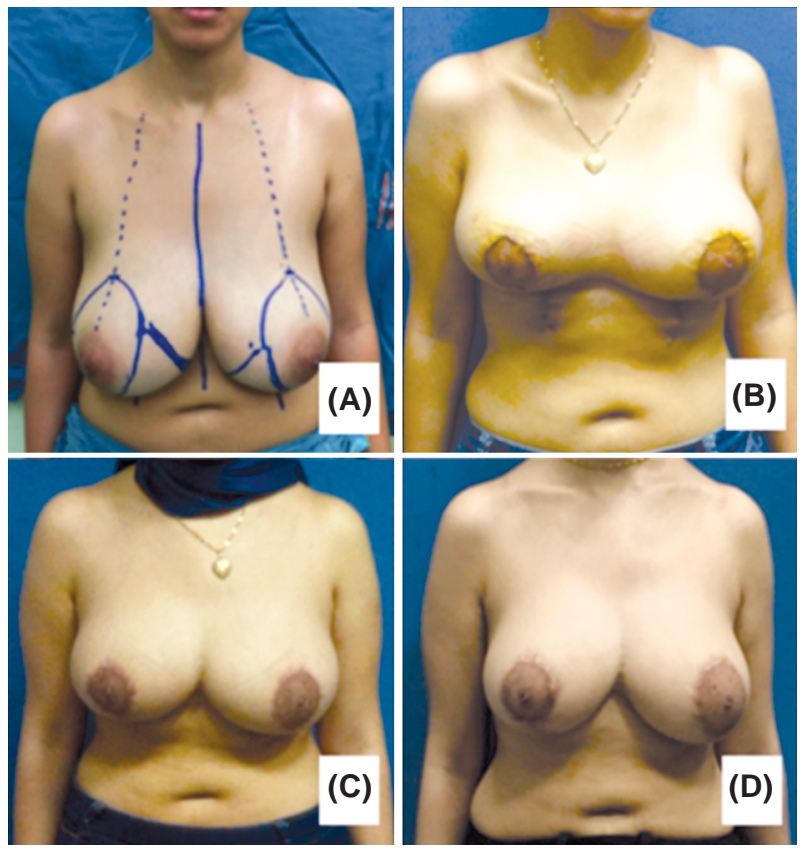

Fig. (2): (A) Pre-operative anteroposterior photo of a 25 years old woman underwent superior pedicle vertical scar reduction mammoplasty (Lejour). (B) 1 month post-operative photo showing decrease of SN-N distance and increased lower pole show. (C) 3 months post-operative showing increase of SN-N distance, decrease in lower pole show, (D) 6 months post-operative showing increase in $\mathrm{SN}-\mathrm{N}$ distance and $\mathrm{t}$ decrease in lower pole show.
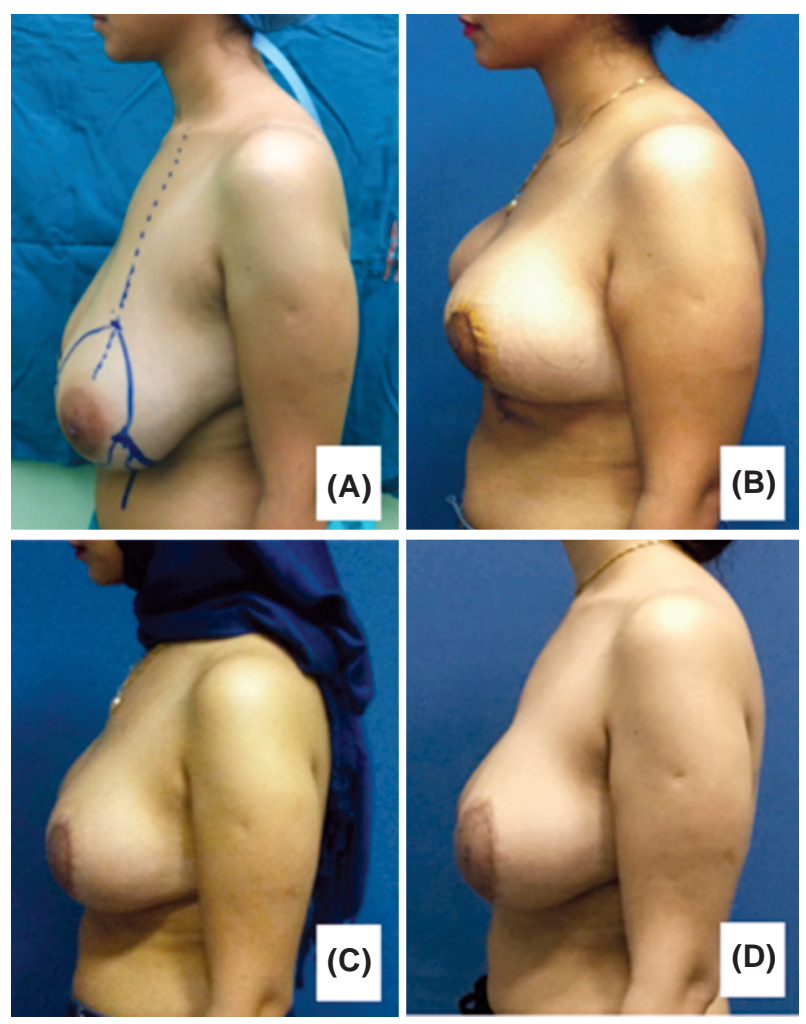

Fig. (3): Same case lateral view (A) Pre-operative. (B) 1 month post-operative showing the nipple projection and exaggerated upper pole fullness. (C) 3 months post-operative showing decrease of nipple projection and upper pole fullness. (D) 6 months post-operative showing decrease of nipple projection and upper pole fullness.

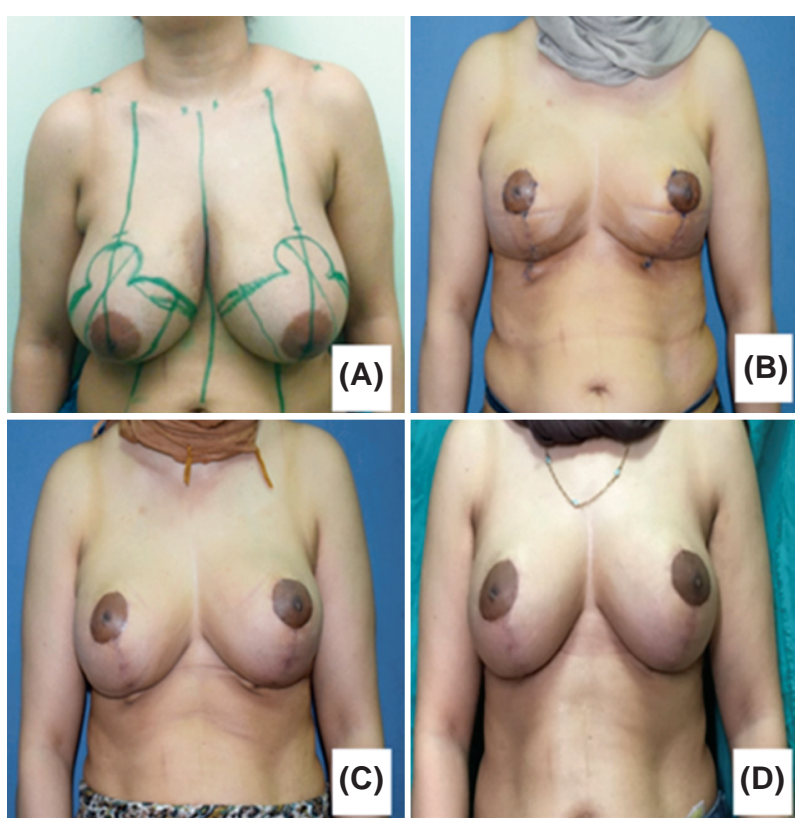

Fig. (4): (A) Pre-operative photo of 35 years old woman underwent medial pedicle vertical scar reduction mammoplasty (hall findlay). (B) 1 month post-operative photo showing significant decrease of SN-N distance and increased lower pole show. (C) 3 months post-operative photo showing decrease in SN-N distance, increase in lower pole show (D) 6 months post-operative photo showing decrease in $\mathrm{SN}-\mathrm{N}$ distance and increase in lower pole show.
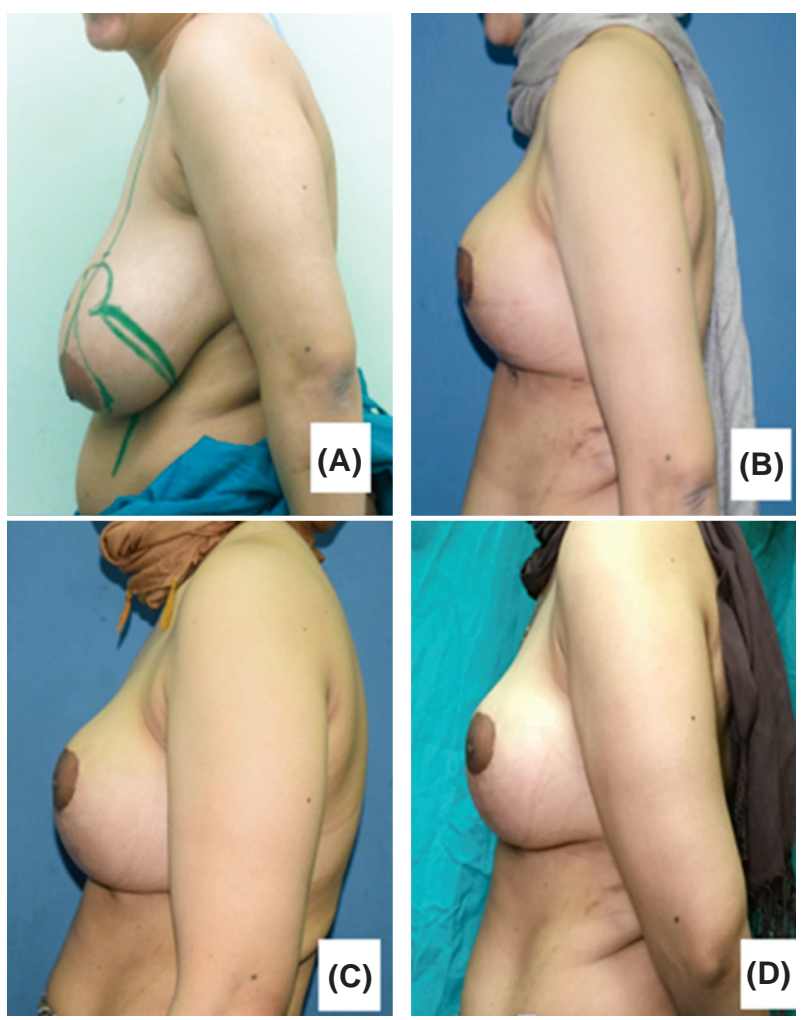

Fig. (5): Same case lateral view (A) Pre-operative. (B) 1 month post-operative showing nipple projection and upper pole fullness. (C) 3 months post-operative showing decrease in nipple projection and upper pole fullness (D) 6 months post-operative photo showing decrease of nipple projection and upper pole fullness. 
Table (1): Comparison between group I and group II according to all pre-operative and intra operative measurements.

\begin{tabular}{lllll}
\hline & $\begin{array}{c}\text { Group I } \\
\text { (Lejour) }\end{array}$ & $\begin{array}{c}\text { Group II } \\
\text { (Findlay) }\end{array}$ & $\begin{array}{c}t \text { - } \\
\text { test }\end{array}$ & $\begin{array}{c}p \text { - } \\
\text { value }\end{array}$ \\
\hline Pre-operative: & & & & \\
$\quad$ SN-N distance & $33.90 \pm 2.45$ & $33.08 \pm 1.99$ & 1.369 & 0.249 \\
Nipple projection & $17.28 \pm 3.19$ & $17.00 \pm 1.53$ & 0.121 & 0.730 \\
Slope at 2 (cm) & $15.73 \pm 3.18$ & $15.53 \pm 1.01$ & 0.072 & 0.790 \\
Slope at 5 (cm) & $13.98 \pm 3.24$ & $13.95 \pm 1.09$ & 0.001 & 0.974 \\
IMF level & $21.55 \pm 1.84$ & $20.45 \pm 2.13$ & 3.047 & 0.089 \\
Lower pole show & $1.09 \pm 0.93$ & $0.88 \pm 0.81$ & 0.502 & 0.484 \\
Lower pole distance & $19.40 \pm 2.60$ & $17.25 \pm 2.22$ & 2.294 & 0.068 \\
Intra-operative: & & & & \\
Scar length & $13.18 \pm 0.88$ & $13.30 \pm 1.75$ & 0.082 & 0.777 \\
\hline
\end{tabular}

SN-N: Sternal Notch to Nipple.

IMF : Inframammary Fold.

Table (2): Comparison between group I and group II according to all measurement in all patients after 1 month.

\begin{tabular}{lllcc}
\hline After 1m & $\begin{array}{c}\text { Group I } \\
\text { (Lejour) }\end{array}$ & $\begin{array}{c}\text { Group II } \\
\text { (Findlay) }\end{array}$ & $\begin{array}{c}t- \\
\text { test }\end{array}$ & $\begin{array}{c}p- \\
\text { value }\end{array}$ \\
\hline SN-N distance & $23.63 \pm 1.91$ & $22.73 \pm 2.05$ & 2.063 & 0.159 \\
Nipple projection & $16.53 \pm 1.67$ & $16.05 \pm 1.23$ & 1.050 & 0.312 \\
Slope at 2 $(\mathrm{cm})$ & $14.35 \pm 1.76$ & $13.40 \pm 1.50$ & 3.367 & 0.074 \\
Slope at 5 $(\mathrm{cm})$ & $12.05 \pm 1.78$ & $11.20 \pm 1.43$ & 2.769 & 0.104 \\
IMF level & $18.95 \pm 1.31$ & $18.45 \pm 2.11$ & 0.813 & 0.373 \\
Lower pole show & $3.63 \pm 1.12$ & $3.25 \pm 1.02$ & 1.374 & 0.175 \\
Lower pole distance & $11.43 \pm 1.79$ & $12.95 \pm 2.70$ & 1.793 & 0.092 \\
Scar length & $13.10 \pm 0.84$ & $13.05 \pm 1.81$ & 0.013 & 0.911 \\
\hline
\end{tabular}

This table shows no statistically significant difference between groups. SN-N: Sternal Notch to Nipple.

IMF : Inframammary Fold.

Table (3): Comparison between group I and group II according to all measurement in all patients after 3 months.

\begin{tabular}{lllcl}
\hline After 3m & $\begin{array}{c}\text { Group I } \\
\text { (Lejour) }\end{array}$ & $\begin{array}{c}\text { Group II } \\
\text { (Findlay) }\end{array}$ & $\begin{array}{c}t- \\
\text { test }\end{array}$ & $\begin{array}{c}p \text { - } \\
\text { value }\end{array}$ \\
\hline SN-N distance & $24.90 \pm 1.83$ & $22.38 \pm 1.98$ & 5.119 & $<0.001$ \\
Nipple projection & $15.70 \pm 1.72$ & $15.30 \pm 1.26$ & 2.336 & 0.042 \\
Slope at 2 (cm) & $13.28 \pm 1.60$ & $12.60 \pm 1.67$ & 2.833 & 0.044 \\
Slope at 5 (cm) & $11.25 \pm 1.59$ & $10.48 \pm 1.70$ & 3.513 & 0.043 \\
IMF level & $18.95 \pm 1.31$ & $18.30 \pm 1.95$ & 1.788 & 0.097 \\
Lower pole show & $2.68 \pm 0.99$ & $4.18 \pm 1.09$ & 5.580 & $<0.001$ \\
Lower pole distance & $11.80 \pm 1.59$ & $13.20 \pm 2.12$ & 2.894 & 0.005 \\
Scar length & $12.70 \pm 0.82$ & $12.95 \pm 1.31$ & 3.025 & 0.004 \\
\hline
\end{tabular}

SN-N: Sternal Notch to Nipple.

IMF : Inframammary Fold.

Table (4): Comparison between group I and group II according to all measurement in all patients after 6 months.

\begin{tabular}{lllll}
\hline After 4m & $\begin{array}{c}\text { Group I } \\
\text { (Lejour) }\end{array}$ & $\begin{array}{c}\text { Group II } \\
\text { (Findlay) }\end{array}$ & $\begin{array}{c}t \text { - } \\
\text { test }\end{array}$ & $\begin{array}{c}p \text { - } \\
\text { value }\end{array}$ \\
\hline SN-N distance & $25.55 \pm 1.90$ & $22.18 \pm 2.05$ & 6.604 & $<0.001$ \\
Nipple projection & $15.00 \pm 1.52$ & $14.90 \pm 1.42$ & 2.643 & 0.049 \\
Slope at 2 (cm) & $12.55 \pm 1.61$ & $12.35 \pm 1.62$ & 2.977 & 0.037 \\
Slope at 5 (cm) & $10.55 \pm 1.67$ & $10.13 \pm 1.37$ & 3.047 & 0.033 \\
IMF level & $18.95 \pm 1.31$ & $18.30 \pm 1.95$ & 1.534 & 0.223 \\
Lower pole show & $2.25 \pm 1.03$ & $4.68 \pm 0.83$ & 13.482 & $<0.001$ \\
Lower pole distance & $11.93 \pm 1.42$ & $13.40 \pm 2.09$ & 3.187 & 0.002 \\
Scar length & $12.10 \pm 0.86$ & $12.88 \pm 1.12$ & 3.025 & 0.004 \\
\hline
\end{tabular}

SN-N: Sternal Notch to Nipple.

IMF : Inframammary Fold.
Table (5): Photographic analysis of group I and group II.

\begin{tabular}{|c|c|c|c|c|c|c|}
\hline & \multicolumn{2}{|c|}{ Group I } & \multicolumn{2}{|c|}{ Group II } & \multicolumn{2}{|c|}{$t$-test } \\
\hline & Mean & $\pm \mathrm{SD}$ & Mean & $\pm \mathrm{SD}$ & $t$ & $p$-value \\
\hline Overall shape & 5.36 & 0.11 & 5.72 & 0.15 & 2.104 & 0.067 \\
\hline Nipple position & 5.30 & 0.12 & 5.53 & 0.23 & 1.325 & 0.424 \\
\hline Areola size & 5.46 & 0.15 & 5.66 & 0.15 & 0.819 & 0.262 \\
\hline Projection & 5.52 & 0.18 & 5.76 & 0.17 & 1.380 & 0.442 \\
\hline Scars & 5.58 & 0.08 & 5.71 & 0.15 & 1.395 & 0.446 \\
\hline Adequacy of reduction & 6.26 & 0.05 & 6.38 & 0.16 & 0.939 & 0.300 \\
\hline
\end{tabular}

This table shows no statistically significant difference between groups.

\section{DISCUSSION}

Breast reduction is a very common procedure done to relief both physical and emotional problems in women with large breasts [5]. Apart from improving symptoms, the goal of surgery should attain aesthetically pleasing breasts with minimal scarring and preservation of NAC sensation [6].

The absence of definitions and measurements makes evaluation of the aesthetic results after breast surgery almost entirely subjective. Recently published clinical studies provided expert opinions [7], algorithms [8], patient questionnaires, complication rates [9] and operating times [10]. They do not directly measure the quality of the aesthetic result, which is essential in any discussion of cosmetic breast surgery. Indeed, measurements are the missing link in the validating cosmetic breast surgery or comparing operations.

Some authors used measurements such as SN$\mathrm{N}$ distance to judge the changes that occur in NAC position and the N-IMF distance for bottoming out evaluation [11-13]. Others used 3D imaging and computer software for evaluation of breast volume changes, redistribution of breast tissue from upper to lower pole and breast projection $[6,14]$.

To the best of our knowledge, no detailed study had yet been performed to objectively compare the post-operative morphological changes that occur after superior pedicle and medial pedicle vertical scar mammoplasty techniques over 6 months duration. In this work we used seven measurements for evaluating and comparing both techniques.

This study showed that there is an increase in SN-N distance 6 months after surgery in the superior pedicle technique with the marked change in the first 3 months after surgery, which corresponds to a study done by Keck et al., [15] on 42 patients that showed increase in SN-N distance by $17 \%$ after 1 year follow-up and similarly the significant change occurred in the first 3 months after surgery. While Eder et al., [13] reported that the increase in 
SN-N distance was significant between 3 and 6 months after surgery on a series of 22 patients.

We attributed this descent in the first 3 months after surgery to the dissection of a tunnel behind the pedicle up to the second rib, this step created dead space which allowed upward movement of the pedicle and exaggeration of upper pole fullness. The pedicle is supported in this position by suturing the medial and lateral pillars decreasing the base with further coning of the breast. This coning effect also causes the lax skin of the superior aspect of the breast to be distributed in a circum horizontal direction directly after surgery. After a period of 3 months these pillars weakens allowing the whole breast to descend by its weight and gravity.

On the contrary our study showed that the SN$\mathrm{N}$ distance using the medial pedicle technique decreased with a significant value against superior pedicle group at 6 months which corresponds to a study done by Small et al., [14] on 15 women underwent short scar medial pedicle reduction mammoplasty, they reported same results over 400-500 days follow-up period attributing their results to the reduction in total breast volume from the early to late post-operative period proved by $3 \mathrm{D}$ volumetric analysis. We attribute our results to the fact that the full thickness dermoglandular pedicle allowed more tissues to descend from the upper pole to the lower pole of the breast below the NAC upon relaxation of the pillars with slightly upward movement of the NAC.

Ahmed and Lista [16] using both superior and medial pedicle vertical scar technique demonstrated non-significant increase of mid clavicle to nipple distance after 4 years follow-up period on 49 consecutive patients attributing their results only to the relaxation of the skin in the upper pole of the breast.

Objective assessment of upper pole fullness in the literature is lacking. Swanson in 2012 [4] was the first to evaluate the upper pole fullness using standardized photographs and computer imaging software. He used this method to compare preoperative and 3 months post-operative photographs of medial pedicle vertical scar reduction mammoplasty technique and inverted $\mathrm{T}$ inferior pedicle technique. He concluded that the medial pedicle vertical scar technique significantly preserves the upper pole fullness while the inverted $\mathrm{T}$ inferior pedicle technique did not.

In our study we created a new and easy method for assessment of upper pole fullness when comparing two breast reduction techniques and we concluded that the superior pedicle technique better preserved the upper pole fullness than the medial pedicle technique over 6 months duration which may be attributed to the thickness of the pedicle. As the thickness of the superior pedicle in our study was about $3 \mathrm{~cm}$ and all of the breast parenchyma and fat behind the pedicle was removed rendering less tissue migration from the upper to the lower pole, so preserving more tissues in the upper pole. On the contrary, more breast tissues was left behind the medial pedicle which descend more by its weight decreasing the upper pole fullness.

In our study assessment of breast projection revealed insignificant decrease over a period of 6 months in superior pedicle technique. We attributed this result to the settlement of the breast on the chest wall by time with relaxation of the pillars which is the main step in exaggerating the projection in vertical scar reduction mammoplasty. This finding is in contradiction to a study done by Eder et al., [13] on 22 patients underwent superior pedicle vertical scar technique according to Lejour demonstrated that the breast projection increased from the early post-operative period up to 12 months follow-up with valuable change between 3-6 months using 3D surface imaging attributing their results to the redistribution of breast tissue from upper to lower pole.

Using the medial pedicle vertical scar technique our results proved decreased breast projection over 6 months duration with only valuable change between 1-3 months which is in line with a study done by Small et al., [14] using 3D scan demonstrated decrease in breast projection by an average of $6.23 \mathrm{~mm}$ between the early (60-120 days) and late (400-500 days) in post-operative period. They stated that their results were attributed to the redistribution of breast tissue from the upper and central portion of the breast to the lower pole supported by $3 \mathrm{D}$ long term volumetric evaluation of superior and inferior poles of the breast. In addition their study showed post-operative bottoming out with $7 \%$ redistribution of breast tissue to the inferior pole of the breast.

Our work demonstrated that the superior pedicle technique better preserved the post-operative projection than the medial pedicle technique, which may be attributed to the plication of the pedicle at a high position to the pectoralis fascia. This result is supported by a study done by Hall Findlay, [17] that demonstrated improvement of the breast projection in 77 patients after undermining the upper pole of the breast up to the second rib and plication of the pedicle at this level. 
The IMF has considerable impact on the appearance of the breast. From the onset of breast development, the IMF anchors the inferior pole of the breast to the chest wall, and with age, the breast becomes ptotic relative to this point. The concept of surgical changes of the IMF has therefore been documented in augmentation mammoplasty, reconstruction mammoplasty and reduction mammoplasty [14].

Our study showed that the IMF level decreased by an average of $2 \mathrm{~cm}$ (becomes higher) in both techniques with no statistically significant difference which is explained by the excision of tissues from the lower pole above the original IMF with redrapping of the skin and creation of the new IMF. Comparable results is shown in a study done by Eder et al., [13] demonstrating drop in the IMF level by an average of $1.8 \mathrm{~cm}$ after 12 months follow-up on 22 patients using the vertical scar reduction mammoplasty technique. Similar results obtained by Small et al., [14] using the short scar medial pedicle technique. They stated that the lateral border of the IMF significantly dropped by $6.27 \mathrm{~mm}$.

Bottoming out is an important factor to consider in all types of reduction mammoplasty procedures. However, few studies up to this date have objectively assessed this phenomenon. As mentioned before our study used the lower pole show and the lower pole distance for assessment of bottoming out, we concluded that bottoming out is more likely to occur in medial pedicle vertical scar technique owing to the significant increase in lower pole show and lower pole distance which is not the case in the superior pedicle vertical scar technique that showed decrease in lower pole show and minimally increase in lower pole distance over 6 months follow-up period.

We believe that redistribution of breast tissue from the upper to the lower pole occurs in all breast reduction procedures with varying degrees according to the weight of the tissues in the upper pole. In our study, the superior dermoglandular pedicle being thinner allowed easy NAC transposition without kinking while the medial pedicle is a full thickness dermoglandular pedicle transposed to the upper pole rendering more tissues pressing on the pillars that migrate to the lower pole below the level of the NAC.

These results corresponded to a study done by Small et al., [14] that objectively investigated the redistribution of breast tissues in short scar medial pedicle technique and concluded $6.5 \%$ redistribu- tion from upper to the lower pole between the early (60-120 days) and late (400-500 days) in the postoperative period. While Eder et al., [13] using the superior pedicle vertical scar reduction mammoplasty showed $21 \%$ redistribution of tissues from the upper pole to the lower pole with significant increase in N-IMF distance between 1 and 6 months post-operatively.

On the contrary Ahmed and Lista, [16] demonstrated that bottoming out does not occur in either superior or medial pedicle vertical scar reduction mammoplasty techniques owing to the decrease in the N-IMF distance after four years follow-up compared to post-operative day five in a series of 49 patients. They attributed these results to the gathering of parenchymal pillars by 4 point gathering box stitches which may give more support to the pillars. Moreover contraction of the vertical scar may have a role in shortening the N-IMF distance. Furthermore this study is limited by the time chosen for follow-up. Based on our finding we believe that their report may be distorted secondary to the post-operative edema of day five which may artificially increase the distance therefore resolution of edema and subsequent bottoming out may have been missed.

Our study revealed a decrease in scar length in both techniques being more significant in the superior pedicle technique. We related this decrease to the scar contraction that occurs more in the superior pedicle technique with concomitant increase in lower pole distance. On the other hand the lower pole distance in the medial pedicle technique increased which overweighs the scar contraction. On the contrary Keck et al., [15] demonstrated an average increase in scar length after vertical scar technique by $22 \%$ after 1 year followup. They did not specify in their article a possible explanation for this as well as did not specify the pedicle used. We attributed this difference in results to the difference in technique such as inadequate resection of breast tissue in the lower pole. The lower pole show in superior pedicle technique showed marked decrease which was unpleasant aesthetically. We attributed that to the fact that the main resection was in the lower pole which is responsible for support.

As regard the photographic analysis of the breast by five evaluators, we noticed that the overall shape and position of the NAC on the breast mound is being better in the medial pedicle technique than superior pedicle technique although statistically insignificant. We attributed this difference to type II statistical error. It appears to us that the ratio 
between the upper pole of the breast (the point of breast take off from the chest) to the nipple and the visual lower pole (lower pole show) which can be noticed from the lateral and anterior views respectively is $3: 1$ in group I and 2:1 in group II.

Although this study didn't perform these measurements clinically further studies can be done to evaluate and find the best ratio for an aesthetically pleasing breast.

A trial identifying specific parameters which contribute to the attractiveness of a breast done by Mallucci and Branford [18] on 100 breast images chosen by the print media demonstrated that the ratio between the upper pole to lower pole (N-IMF distance) should be 45\%:55\% respectively and any deviation from this ratio is considered unattractive breast. This observational study used the print media rather than clinical photographs where the models can make slight alteration in their posture to make their breasts more attractive.

Furthermore we believe that comparison should be made between the upper pole of the breast and the lower pole show as the posterior part of the NIMF distance may be hidden behind the breast lower pole with very little show which is considered less attractive.

Complications after vertical scar techniques represent a spectrum of severity from issues requiring conservative management to conditions requiring hospitalization and surgery [19].

Both the superior and medial pedicle techniques in our study share in common the absence of hematoma and seroma. The use of suction drains, less undermining and no liposuction may be responsible for the low rate of seroma and hematoma in our study. Wound complications in the vertical scar in both techniques may be attributed to the use of suture material that led to foreign body reactions which was managed conservatively, and healing occurred by secondary intention, complete healing took about two to three weeks with no need for revision.

Glandular necrosis and infection occurred in one breast in the superior pedicle group noticing yellowish brown discharge coming out from the lower third of the vertical scar followed by disruption of sutures in this area. This complication was managed by broad spectrum antibiotics and daily dressing for 1 week followed by minimal debridement and 2ry sutures.

Partial areola loss occurred in one case in group II groups mostly due to kink of the pedicle resulting in congestion which was managed conservatively and complete healing occurred after 3 weeks of daily dressing.

Several factors make it difficult to compare between studies as regard the complications. These factors include the post-operative care, the steep learning curve of vertical scar techniques, the difference in breast volumes and the weight of excised breast tissue as small breasts have lower rate of complications.

Finally, we concluded that both techniques are aesthetically reliable with bottoming out more in Findlay technique after a follow-up of 6 months duration. However, lower pole show is less in Lejour technique which may be questionable to patient from aesthetic point of view. So, we recommend using the lower norms in picking up NAC complex level in Findlay technique to compensate for bottoming out and ensuring the proper position of NAC in relation to breast mound, also maintain good thickness of pillars in superior technique to minimize the presence of unpleasant small lower pole.

We also introduced two new measurements (upper pole fullness, lower pole show) that can be used for comparison between different techniques used in breast reduction surgery.

\section{REFERENCES}

1- Berthe J.V., Massaut J., Greuse M., Coessens B. and De Mey A.: The Vertical Mammaplasty: A Reappraisal of the Technique and Its Complications: Plast. Reconstr. Surg., 111 (7): 2192-2199, 2003.

2- Lejour M. and Abboud M.: Vertical mammaplasty without inframammary scar and with breast liposuction: Perspect. Plast. Surg., 4: 67, 1990.

3- Hall-Findlay E.J.: A simplified vertical reduction mammaplasty: Shortening the learning curve: Plast. Reconstr. Surg., 104: 748, 1999.

4- Swanson E.: A Measurement System for Evaluation of Shape Changes and Proportions after Cosmetic Breast Surgery: Plast. Reconstr. Surg., 129: 982-992, 2012.

5- Mizgala C.L. and MacKenzie K.M.: Breast reduction outcome study: Ann. Plast. Surg., 44: 125e33, 2000.

6- Quan M., Fadl A., Small K., Tepper O., Kumar N., Choi M. and Karp N.: Defining Pseudoptosis (Bottoming Out) 3 Years After Short-Scar Medial Pedicle Breast Reduction Aesth. Plast. Surg., 35: 357-364, 2011.

7- Blondeel P.N., Hijjawi J., Depypere H., Roche N. and Van Landuyt K.: Shaping the breast in aesthetic and reconstructive breast surgery: An easy three-step principle. Part IV-Aesthetic breast surgery: Plast. Reconstr. Surg., 124: 372-382, 2009.

8- Colwell A.S., Driscoll D. and Breuing K.H.: Mastopexy techniques after massive weight loss: An algorithmic 
approach and review of the literature: Ann. Plast. Surg., 63: 28-33, 2009.

9- Cho B.C., Yang J.D. and Baik B.S.: Periareolar reduction mammoplasty using an inferior dermal pedicle or a central pedicle: J. Plast. Reconstr. Aesthet. Surg., 61: 275-281, 2008.

10- Carty M.J., Chan R., Huckman R., Snow D. and Orgill D.P.: A detailed analysis of the reduction mammaplasty learning curve: A statistical process model for approaching surgical performance improvement: Plast. Reconstr. Surg., 124: 706-714, 2009.

11- Reus W.F. and Mathes S.J.: Preservation of projection after reduction mammaplasty: Long term follow-up of the inferior pedicle technique: Plast. Reconstr. Surg., 82: 644, 1998.

12- Erdogan B., Ayhan M., Deren O. and Tunsel A.: Importance of pedicle length in inferior pedicle technique and longterm outcome of areola to fold distance: Aesthetic Plast. Surg., 26: 436, 2002.

13- Eder M., Kloppel M., Muller D., Papadopulos N.A., Machens H. and Kovacs L.: 3-D analysis of breast morphology changes after inverted T-scar and vertical-scar reduction mammoplasty over 12 months: J. Plast. Surg., 66: 776-786, 2013.
14- Small K., Tepper O., Unger J., Kumar N., Feldman D., Choi M. and Karp N.: Re defining pseudoptosis from a 3D perspective after short scar-medial pedicle reduction mammaplasty Journal of Plastic, Reconstructive \& Aesthetic Surgery, 63: 346-353, 2010.

15- Keck M., Kaye K., Thieme I. and Ueberreiter K.: Vertical mammaplasty: Post-operative changes, complications and patient evaluation: Can. J. Plast. Surg., 15: (1): 41-43, 2007.

16- Ahmed J. and Lista F.: Vertical scar reduction mammaplasty: A 15-year experience including a review of 250 consecutive cases. Plast. Reconstr. Surg., 117 (7): 215265, 2006.

17- Hall-Findlay E.J.: The Three Breast Dimensions: Analysis and Effecting Change: Plast. Reconstr. Surg., 125: 16321642,2010

18- Malluci P. and Branford O.A.: Concepts in breast dimensions: Analysis of the ideal breast; Journal of Plastic, Reconstructive and Aesthetic Surgery, 65: 8-16, 2012.

19- Adham M., Sawan K., Lovelace C., Jaeger N.J. and Adham C.: Unfavorable Outcomes with Vertical Reduction Mammaplasty: Part II. Aesthetic Surgery Journal, 31 (1): 4046, 2011. 